\title{
KEANEKARAGAMAN PINANGA SP. DI RESORT PTN SELABINTANA-SEKSI PTN WILAYAH III-BIDANG PTN WILAYAH II SUKABUMI TAMAN NASIONAL GUNUNG GEDE PANGRANGO
}

\author{
Indri Yani ${ }^{\left.a^{*}\right)}$, Imelianti a), Teguh Prasetyo ${ }^{\text {a) }}$, Bella Salsabilla ${ }^{\text {a) }}$, Elisa Rosiana ${ }^{\text {a) }}$ \\ a) Universitas Pakuan, Kota Bogor, Indonesia \\ *) e-mail korespondensi: indri@unpak.ac.id
}

\section{Riwayat Artikel}

diterima 17 November 2021 direvisi 30 November 2021 disetujui 30 Desember 2021

\begin{abstract}
Abstrak.
Pinanga sp. merupakan salah satu jenis tumbuhan monokotil yang tergolong palem- paleman. Pinanga sp. ini masuk kedalam famili Arecaceae. Penelitian ini bertujuan untuk mengidentifikasi jenis-jenis pinang di kawasan Gunung Gede Pangrango. Gunung Gede Pangrango merupakan salah satu wilayah kawasan konservasi pertama di Indonesia yang ditetapkan sebagai Cagar Alam Cibodas pada tahun 1889 yang memiliki keanekaragaman Pinang. Metode yang digunakan adalah metode deskriptif eksploratif. Sementara pengambilan data dilakukan dengan observasi langsung menggunakan metode strip sensus yaitu metode penelitian yang dilakukan dengan cara berjalan disepanjang garis transek, serta mencatat spesies-spesies yang diamati disepanjang garis transek tersebut. Hasil penelitian menunjukkan spesies dalam famili Arecaceae ditemukan di Resort PTN Selabintana-Seksi PTN Wilayah III-Bidang PTN Wilayah II Sukabumi Taman Nasional Gunung Gede Pangrango adalah sebanyak 3 spesies yaitu Caryota maxima, Curculigo cavitulata, dan Pinanga javana.
\end{abstract}

Kata Kunci: Keanekaragaman, Pinanga sp., Resort PTN Selabintana

\section{DIVERSITY OF PINANGA SP. IN THE RESORT OF PTN SELABINTANA - SECTION OF PTN REGION III - SECTION OF PTN REGION II SUKABUMI NATIONAL PARK OF MOUNT GEDE PANGRANGO}

\begin{abstract}
Pinanga sp. is one type of monocotyledonous plant belonging to the palms. Pinanga sp. It belongs to the Arecaceae family. This study aims to identify the types of areca nut in the area of Mount Gede Pangrango. Mount Gede Pangrango is one of the first conservation areas in Indonesia which was designated as a Cibodas Nature Reserve in 1889 which has a variety of areca nut. The method used is descriptive exploratory method. While data collection was carried out by direct observation using the census strip method, the research method was carried out by walking along the transect line, and recording the species observed along the transect line. The results showed that there were 3 species in the Arecaceae family found in Resort PTN Selabintana-Section PTN Region III-Section PTN Region II Sukabumi Gunung Gede Pangrango National Park, namely Caryota maxima, Curculigo capitulate, and Pinanga javana.
\end{abstract}

Keywords: Diversity, Pinanga sp., Resort PTN Selabintana

Arecacea merupakan merupakan sekelompok tumbuhan berbunga yang banyak anggotanya sehingga memiliki nilai penting dalam kehidupan manusia. Famili Arecaceae termasuk kedalam ordo Arecales. Famili Arecaceae memiliki 225 anggota genere dan memiliki lebih dari 2600 spesies (Cantik,2021). Pinanga sp. termasuk kedalam famili Arecaceae. Pinanga sp. dapat tumbuh dan tersebar di berbagai negara salah satu nya Indonesia khususnya di Resort Selabintana Seksi PTN Wilayah IIIBidang PTN Wilayah II Sukabumi Taman Nasional Gunung Gede Pangrango yang sebagian besar ditumbuhi oleh Pinanga sp.

Gunung gede pangrango ini sudah ditetapkan sebagai kawasan Taman Nasional Gede Pangrango. Hal ini dikarenakan kawasan tersebut merupakan tempat atau habitat dari hewan- hewan langka yang dilindungi seperti Lutung Surili, Owa Jawa, Macan Tutul, Biul, Anjing Ajag dan masih banyak lainnya. Selain itu, kawasan konservasi alam ini juga ditumbuhi spesies tumbuh-tumbuhan unik serta banyak manfaat nya salah satu nya yaitu Pinanga sp.
Penelitian ini bertujuan untuk mengetahui keanekaragaman Pinanga sp. di kawasan konservasi Resort Selabintana Seksi PTN Wilayah III-Bidang PTN Wilayah II Sukabumi Taman Nasional Gunung Gede Pangrango.

\section{METODOLOGI PENELITIAN}

Metode yang digunakan adalah metode deskriptif eksploratif yang menggambarkan identifikasi pinangpinangan. Sementara dalam pengambilan data dilakukan observasi langsung dengan menggunakan metode strip sensus. Data yang diambil meliputi data primer yang di dapat secara langsung di lapangan dan data sekunder yang diambil untuk mendukung data primer yang berasal dari sumber-sumber lain yang relevan.

Penelitian ini dilaksanakan di Resort PTN Selabintana-Seksi PTN Wilayah III-Bidang PTN Wilayah II Sukabumi Taman Nasional Gunung Gede Pangrango.

Teknik pengambilan data pada penelitian ini yaitu dilakukan dengan cara mengidentifikasi secara langsung di lapangan dengan bantuan aplikasi picture this. Kemudian mendokumentasikan tiap spesies yang ditemukan untuk menambah keakuratan dalam identifikasi jenis pinang- 
pinangan. Lalu, sampel yang ditemukan diidentifikasi hingga tingkat spesies.

\section{HASIL PENELITIAN DAN PEMBAHASAN}

Pinang yang ditemukan di lokasi penelitian yaitu Resort PTN Selabintana Taman Nasional Gunung Gede Pangrango ini beragam. Terdapat sekitar 3 spesies pinang yang ditemukan yaitu Caryota maxima, Curcurligo cavitulata, dan Pinanga javana. Dari 3 spesies pinang tersebut memiliki karakteristik yang berbeda-beda. Hasil observasi atau penelitian dapat dilihat pada tabel berikut.

Tabel 1. Lokasi Penelitian dan Jenis Pinang di Resort Selabintana TNGGP

\begin{tabular}{ccccc}
\hline \multirow{3}{*}{ Jenis } & \multicolumn{3}{c}{ Lokasi } & \\
\cline { 2 - 4 } Pinanga & $\mathbf{1}$ & $\mathbf{2}$ & $\mathbf{3}$ & Jumlah \\
& $\begin{array}{c}(\mathbf{1 1 3 5} \\
\text { Mdpl) })\end{array}$ & $\begin{array}{c}(\mathbf{1 3 0 0} \\
\text { Mdpl) })\end{array}$ & $\begin{array}{c}(\mathbf{1 4 0 0} \\
\text { Mdpl) })\end{array}$ & \\
\hline $\begin{array}{c}\text { Caryota } \\
\text { maxima }\end{array}$ & 3 & 3 & 1 & 20 \\
$\begin{array}{c}\text { Curculigo } \\
\text { cavitulata }\end{array}$ & 2 & 4 & 8 & 14 \\
$\begin{array}{c}\text { Pinanga } \\
\text { javana }\end{array}$ & 43 & 0 & 0 & 43 \\
\hline
\end{tabular}

Pada tabel 1 menunjukkan bahwa pada ketinggian 1135 Mdpl ini didominasi oleh spesies Pinanga javana dengan jumlah 43 pohon pinang jawa. Selain itu, terdapat Caryota maxima yang ditemukan sekitar 3 pohon, dan Curculigo cavitulata atau pinang congkok sekitar 2 pohon. Sedangkan, pada ketinggian 1300-1400 Mdpl. Pinang Jawa ini tidak ditemukan dan hanya didominasi oleh pinang hutan dan pinang congkok. Hal ini menunjukkan bahwa semakin tinggi permukaannya tumbuh, Pinang Jawa ini semakin sulit ditemukan. Hal ini sesuai dengan deskripsi mengenai pinang yang dikutip dari Tempo. $C O$ bahwa pinang ini akan dapat tumbuh dan bereproduksi secara optimal itu pada ketinggian 0 - $1.000 \mathrm{Mdpl}$. Selain itu, pinang Jawa ini dapat tumbuh hingga ketinggian $1.400 \mathrm{Mdpl}$. Pinang ini akan tumbuh pada tanah yang subur dan gembur serta banyak humus.

Klasifikasi dan karakteristik jenis pinang yang ditemukan di Resort Selabintana TNGGP.

$\begin{array}{ll}\text { Caryota maxima } & \\ \text { Kingdom } & \text { : Plantae } \\ \text { Divisi } & \text { : Magnoliophyta } \\ \text { Kelas } & \text { : Liliopsida } \\ \text { Ordo } & \text { : Arecales } \\ \text { Famili } & \text { : Arecaceae } \\ \text { Genus } & : \text { Caryota } \\ \text { Spesies } & : \text { Caryota maxima }\end{array}$

Caryota maxima merupakan spesies pinang yang sangat besar dengan tinggi $33 \mathrm{~m}$ dengan poros mahkota halus yang sangat panjang. Batangnya berkoloni, tegak, dengan tinggi $30-33 \mathrm{~m}$ dan diameter $30 \mathrm{~cm}$. Selain itu, batangnya bercabang dua, tidak rangka dengan panjang $5 \mathrm{~m}$, warna daun hijau kusam, dan terjumbai tumbuh di satu bidang. Selebarannya berbentuk obdeltoid dan praemorse. Bunganya berukuran besar dengan panjang 1-1,5 m dengan bunga jantan dan bunga putik yang terletak pada perbungaan yang sama. Panjang buahnya mencapai $2,5 \mathrm{~cm}$ dan berwarna merah muda hingga ungu kemerahan tua saat matang (Eldric, 2016). Gambar Caryota maxima dapat dilihat pada gambar 1 berikut ini.

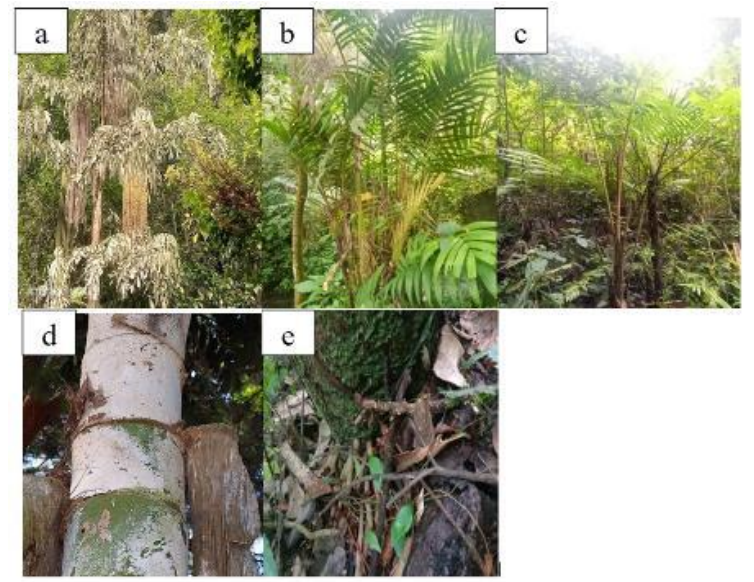

Gambar 1: Caryota maxima. a) Buah. b) Daun. c) Pohon. d) Batang (Palmedia, 2016). e).Akar.

$\begin{array}{ll}\text { Curculigo cavitulata } \\ \text { Kingdom } & \text { : Plantae } \\ \text { Divisi } & \text { : Magnoliophyta } \\ \text { Kelas } & \text { : Liliopsida } \\ \text { Ordo } & \text { : Liliales } \\ \text { Famili } & \text { : Amaryllidaceae } \\ \text { Genus } & : \text { Curculigo } \\ \text { Spesies } & : \text { Curculigo cavitulata }\end{array}$

Curculigo cavitulata merupakan tumbuhan herba tahunan, berambut atau gundul, dengan rhizoma tebal. Daun radikal, biasanya bertangkai, menggaris sampai mendekati ellips. Inflorescence racemus atau tandan, kadang seperti kepala, dengan sedikit atau banyak bunga; tepala bersatu dalam tabung pendek atau memanjang; benang sari 6 , bebas; pistil dengan 3 sel ovarium, stilus pendek, kolumner, berakhir pada 3 stigma yang panjang.

Buah berdaging, seperti berry, indehiscent atau secara tak teratur dehiscent, biji sedikit. Biji berwarna hitam, agak membulat. Curculigo cavitulata Kuntze.. herba berambut, panjang mencapai 1,5 $\mathrm{m}$. Panjang tangkai daun mencapai $1 \mathrm{~m}$; helaian daun ellips, $60-150 \mathrm{~cm}$ x $5-15 \mathrm{~cm}$, gundul. Inflorescence racemus seperti kepala, $2.5-7 \mathrm{~cm} \mathrm{x}$ $2.5-7 \mathrm{~cm}$; panjang pedunculus 7-30 $\mathrm{cm}$, berambut halus sampai gundul saat berbuah; panjang bractea $1.5-5 \mathrm{~cm}$, kecoklatan, saat berbuah berambut hingga gundul; bunga kuning, berambut, subsessile; panjang tabung perianthium 1-2 mm, panjang lobes 6-8 mm (Dryand, 2021). Gambar Curculigo cavitulata dapat dilihat gambar 2 berikut ini. 


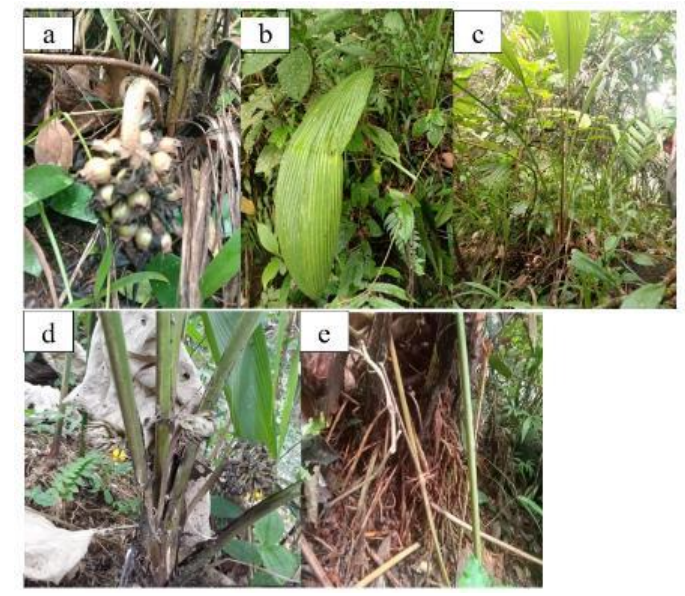

Gambar 2: Curculigo cavitulata. a) Buah. b) Daun. c) Pohon. d) Batang (e). Akar.

$\begin{array}{ll}\text { Pinanga javana } & \\ \text { Kingdom } & \text { : Plantae } \\ \text { Divisi } & \text { : Magnoliophyta } \\ \text { Kelas } & \text { : Liliopsida } \\ \text { Ordo } & \text { : Arecales } \\ \text { Famili } & \text { : Arecaceae } \\ \text { Genus } & \text { : Pinanga } \\ \text { Spesies } & \text { : Pinanga javana }\end{array}$

Pinanga javana (Pinang Jawa) merupakan tumbuhan endemik yang hanya terdapat di pulau Jawa dengan daerah persebaran yang terbatas. Pinang Jawa ini memiliki batang yang tunggal, tinggi $10 \mathrm{~m}$, diameteter $810 \mathrm{~cm}$, beruas jelas dan tajuk pelepahnya berwarna hijau. Panjang tangkai daun sampai $50 \mathrm{~cm}$, panjang tulang daun $1,52 \mathrm{~m}$, dan susunan helai daunnya ini menyirip. Bunga akan tumbuh pada ruas batang di bawah tajuk pelepah dengan bentuk malai dan menggantung dan tiap tandan terdiri atas 15-16 triads (satu betina diapit oleh dua bunga jantan) dan biasanya bunga betina akan mekar lebih dahulu daripada jantan. Buah nya berbentuk bulat telur dengan diameter $15 \mathrm{~mm}$, panjang 20 $\mathrm{mm}$ dan berwarna merah kehitam-hitaman dan berbiji satu (Witono, 2000). Gambar Pinanga javana dapat dilihat pada gambar 3 berikut ini.

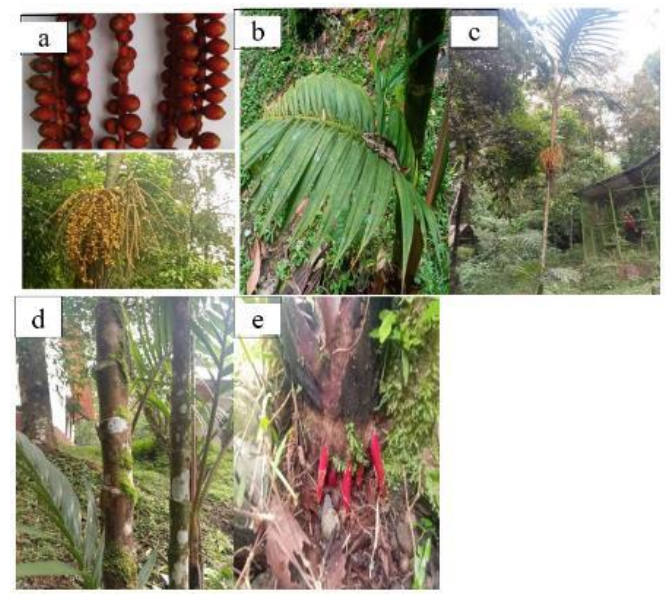

Gambar 3: Pinanga javana. a) Buah (Rizmon Nurul Z., 2020). b) Daun. c) Pohon. d) Batang (Palmedia. Net, 2021). e). Akar.
Hasil penelitian menujukkan keanekaragaman Pinanga sp. terdapat 77 pohon di Resort PTN Selabintana Taman Nasional Gunung Gede Pangrango. Dari jumlah keseluruhan spesies yang ditemukan, yakni terdapat tiga jenis spesies yang terdiri dari 3 genus yaitu Caryota, Curculigo, dan Pinanga.

Berdasarkan jumlah pohonnya, Pinanga javana atau sering dikenal dengan Pinang Jawa memiliki jumlah paling banyak yaitu 43 pohon. Tumbuhan ini paling banyak ditemukan di ketinggian $1135 \mathrm{Mdpl}$ dengan kondisi suhu tanah $21-24^{\circ} \mathrm{C}$ dengan kondisi tanah yang subur dan gembur serta banyak mengandung humus (Witono, 2000).

Jumlah pohon terbanyak kedua adalah aryota maxima atau yang lebih dikenal dengan Pinang Himalaya dengan jumlah pohon sebanyak 20 pohon. Pinang ini banyaktumbuh di ketinggian 1400 Mdpl. Tumbuhan ini akan tumbuh di daerah tropis dengan kondisi tanah yang gembur dan lembab (Palmedia, 2016).

Spesies dengan jumlah pohon yang paling sedikit jumlahnya adalah Curculigo cavitulata sebanyak 14 pohon. Tumbuhan ini banyak di temukan di ketinggian sekitar 1400 Mdpl. Curculigo cavitulata merupakan tanaman yang menyukai keteduhan atau kondisi tanpa adanya sinar matahari. Tumbuhan ini berukuran sangat kecil dan menyukai tanah yang subur, pengairan yang cukup dan kaya akan bahan organik (Yaya Suryana, 2012).

\section{KESIMPULAN}

Berdasarkan hasil penelitian yang telah dilakukan, maka dapat disimpulkan bahwa spesies dalam famili Arecaceae yaitu Pinanga sp. yang ditemukan di Kawasan konservasi Resort PTN Selabintana Taman Nasional Gunung Gede Pangrango adalah sebanyak 3 jenis spesies yaitu Caryota maxima, Curculigo cavitulata, dan Pinanga javana.

\section{REFERENSI}

Anggraini, Novi. 2021. Identifikasi Myrtaceae di Kawasan Konservasi Hutan Kerangas Desa Cendil Pulau Belitung sebagai Media Pembelajaran Biologi. Bogor : Universitas Pakuan.

Cantiq. Tanpa Tahun. Arecaeae. https://www.scribd.com/document/377030616/Arec aceae. (Diakses pada tanggal 20 Desember 2021).

Konakid. 2016. Caryota maxima. http://www.palmpedia.net/wiki/Caryota_maxima. (Diakses pada tanggal 20 Desember 2021).

Noerkwoliz.Tanpa Tahun. Metode Transek. https://noerkwoliz.wordpress.com/2011/05/15/meto de-transek/. (Diakses pada tanggal 20 Desember 2021).

Rusyana, Yaya. 2011. Congkok (Curculigocavitulata). http://floranegeriku.blogspot.com/2011/06/congkokcurculigo-cavitulata-gaertn.html. (Diakses pada tanggal 20 Desember 2021).

Syahidah, Dewi Nur dan Niken Kusumarini. (2020). Keanekaragaman Tumbuhan di Sekitar Mata Air Sumur Gedhe Desa Tanjungsekar Kecamatan 
Pucakwangi Kabupaten Pati. E-ISSN 2656-3436/ PISSN 2615-3947 Journal of Biology Education Vol 3 No 2 (2020) halaman 168-177.

Zulkarnaen, Rizmoon Nurul (dkk). 2020. The Growth and Distribution Pattern of Endemic Java Palm (Pinanga javana Blume) in Mt. Slamet, Central Java, Indonesia. Depok : AIP PUBLISHING. 